\title{
SOIL MOISTURE EFFECTS ON ROOT ROT OF WHITE CLOVER CAUSED BY CODINAEA FERTILIS
}

\author{
N.W.WAIPARA ${ }^{1,3}$, M.E. DI MENNA ${ }^{1}$, A.L.J. COLE ${ }^{3}$ and R.A. SKIPP ${ }^{2}$ \\ ${ }^{1}$ New Zealand Pastoral Agriculture Research Institute, \\ Private Bag 3123, Hamilton \\ ${ }^{2}$ Private Bag 11008, Palmerston North \\ ${ }^{3}$ University of Canterbury, Private Bag 4800, Christchurch
}

\begin{abstract}
The fungus Codinaea fertilis is frequently isolated from roots of pasture plants in warm areas of New Zealand. Its pathogenicity to white clover plants was assessed in a pot experiment in which soil moisture was maintained at $40,50,60$, and $80 \%$ of water holding capacity (WHC). Mean root and shoot dry weights were lower in plants inoculated with conidia of $C$. fertilisthan in uninoculated plants, particularly at low soil moisture (40\% and 50\% WHC). Roots of inoculated plants showed disease symptoms of discoloration and rot. The ability of $C$. fertilis to reduce growth and yield of white clover at low soil moisture suggests that it may be an important cause of declining productivity and persistence in drought prone North Island pastures.

Keywords: Codinaea fertilis, white clover, pathogen, soil moisture
\end{abstract}

\section{INTRODUCTION}

Poor persistence of forage legumes such as white clover (Trifolium repens L.) has often been attributed to the action of pathogenic root-invading fungi (Leath 1989). Codinaea fertilis Kendrick \& Hughes, a root-invading hyphomycete fungus, can cause substantial root rotting of white clover and other forage legumes (Campbell 1980, 1982; Skipp and Christensen 1982; Waipara et al. 1996). This fungus has frequently been isolated from roots of white clover (Skipp and Christensen 1983) and perennial ryegrass (Skipp and Christensen 1989) in warm areas of New Zealand (North Island and north west of the South Island), and comprised almost $10 \%$ of all isolates obtained in a recent mycological survey of eight pasture plant species in the Waikato (Waipara unpublished). Menzies (1973) suggested that the widespread disappearance of white clover from some pastures, particularly in drought prone eastern areas of the North Island, may have been caused by $C$. fertilis root rot. The present study investigated the influence of soil moisture on the pathogenicity of C. fertilis to white clover as reflected in root and shoot growth.

\section{MATERIALS AND METHODS}

Clover seeds were sown into pots (five per pot) containing $70 \mathrm{~g}$ of fumigated Horotiu sandy loam soil (Vitric Hapuland) which had a pH of 5.6. The soil was fumigated with chloroform to remove existing pathogens (Jenkinson and Powlson 1976a). Pots were then watered to four levels of soil moisture content; $40 \%, 50 \%, 60 \%$ and $80 \%$ water holding capacity (WHC) using the method described by Jenkinson and Powlson (1976b). Five week old plants were inoculated with two strains of C. fertilis; strain 1 (Cod C1R6.1) was isolated from white clover roots and strain 2 (Cod R2R6.1) from perennial ryegrass roots. Both strains were isolated from Waikato dairy pasture, and are stored in $10 \%$ glycerol at $-20^{\circ} \mathrm{C}$ in the EPM microfungi culture collection, AgResearch, Ruakura Agricultural Centre, Hamilton. Plants in each pot were inoculated with $15 \mathrm{ml}$ of conidial suspensions $\left(10^{7}\right.$ conidia $\left./ \mathrm{ml}\right)$, produced by growing each strain on potato carrot agar sloped in milk bottles at $25^{\circ} \mathrm{C}$ for 3 weeks. The suspension was 
pipetted into the soil of each pot to $10 \mathrm{~cm}$ depth (measured with a marked pipette tip), and pots were inoculated twice, 3 days apart, to ensure dissemination of conidia through the soil. Control plants were inoculated with sterilised (autoclaved at $121^{\circ} \mathrm{C}$ for $20 \mathrm{~min}$.) conidial suspensions. Plants were grown at $20^{\circ} \mathrm{C}$ for a further 4 weeks under artificial illumination (110m Einsteins $\mathrm{m}^{-2} \mathrm{sec}^{-1}$ ) with a $16 \mathrm{~h}$ light and $8 \mathrm{~h}$ dark photoperiod and were watered by weight periodically to maintain the four moisture regimes. Each soil moisture treatment was replicated five times for each strain and the control.

After 4 weeks growth, plants were removed and washed free of soil. Roots were visually assessed for percentage root area that was affected by root rot and each plant was assigned a root disease score $0-5$ as follows: $0=$ Lesions and necrosis absent from roots; $1=1-20 \%$ of total root area necrotic; $2=21-40 \%$ of total root area necrotic; 3 $=41-60 \%$ of total root area necrotic; $4=61-80 \%$ of total root area necrotic; $5=81$ $100 \%$ of total root area necrotic. Surface sterilised $3 \mathrm{~mm}$ root segments (10 from each plant) were plated onto water agar to reisolate $C$. fertilis at the conclusion of the experiment. Root and shoot components were then dried in an oven for $48 \mathrm{~h}$ at $60^{\circ} \mathrm{C}$ to determine dry weight yields. All data were analysed by analysis of variance using LSD tests for mean separation.

\section{RESULTS AND DISCUSSION}

C. fertilis was reisolated from discolored and lesioned root segments of inoculated plants from all soil moisture treatments. Mean root and shoot dry weights of inoculated plants were all lower $(\mathrm{P}<0.01)$ than control plant yields at all soil moisture contents except at $80 \%$ WHC, where reduced root and shoot weights of strain 2 were not significantly lower than the controls (Figs.1 and 2). Mean root dry weights in all three treatments decreased as the soil moisture content decreased (Fig. 1), this effect being most noticeable at $40 \%$ and $50 \%$ WHC where the yield of inoculated plants was half that of the controls. Mean shoot dry weights also decreased as soil moisture decreased (Fig. 2), with both control and inoculated plants grown in soil of $40 \%$ WHC again having the lowest shoot yields.

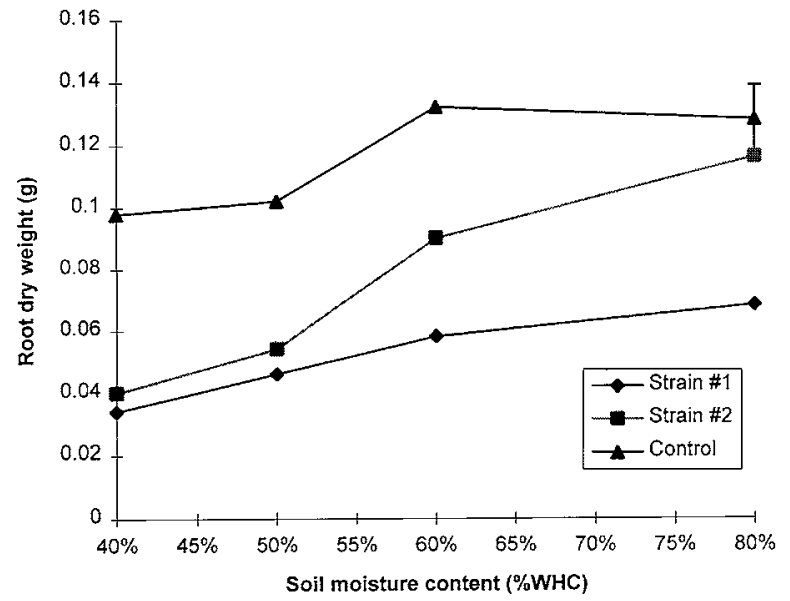

FIGURE 1: Mean root dry weight of white clover plants inoculated with C. fertilis and maintained at four levels of soil moisture. Error bar $=$ SED $($ for all treatments $), \mathbf{0 . 0 3 4}$. 


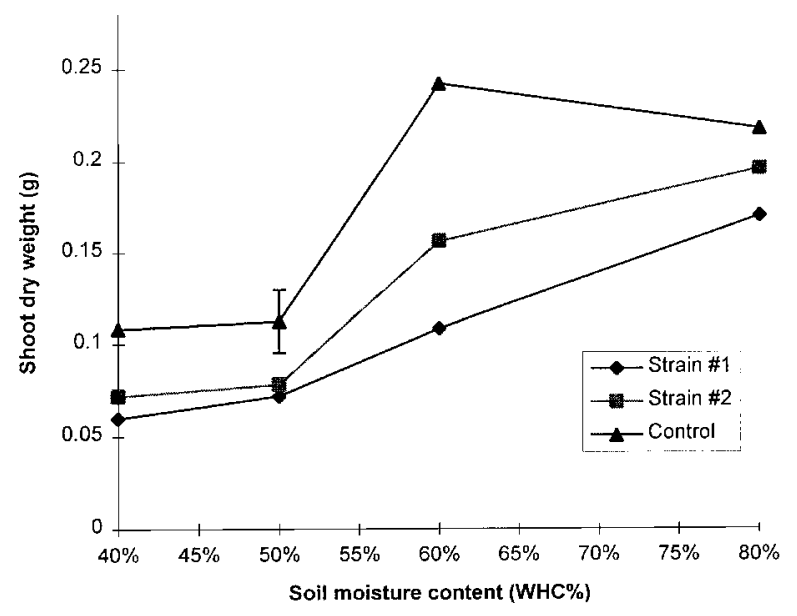

FIGURE 2: Mean shoot dry weight of white clover plants inoculated with C. fertilis and maintained at four levels of soil moisture. Error bar = SED (for all treatments), 0.021 .

Strain 1 of $C$. fertilis was more pathogenic to white clover than strain 2, particularly at higher soil moisture contents. Mean dry weight yields of plants inoculated with strain 1 were lower $(\mathrm{P}<0.01)$ at $80 \%$ WHC than those of plants from strain 2 and the controls (Figs. 1 and 2). Soil moisture affected the pathogenicity of C. fertilis, where plants not under water stress were less susceptible to yield loss and root damage than water-stressed plants. The difference in root and shoot yield reduction caused by the two strains indicates that the fungus has variable pathogenicity to white clover.

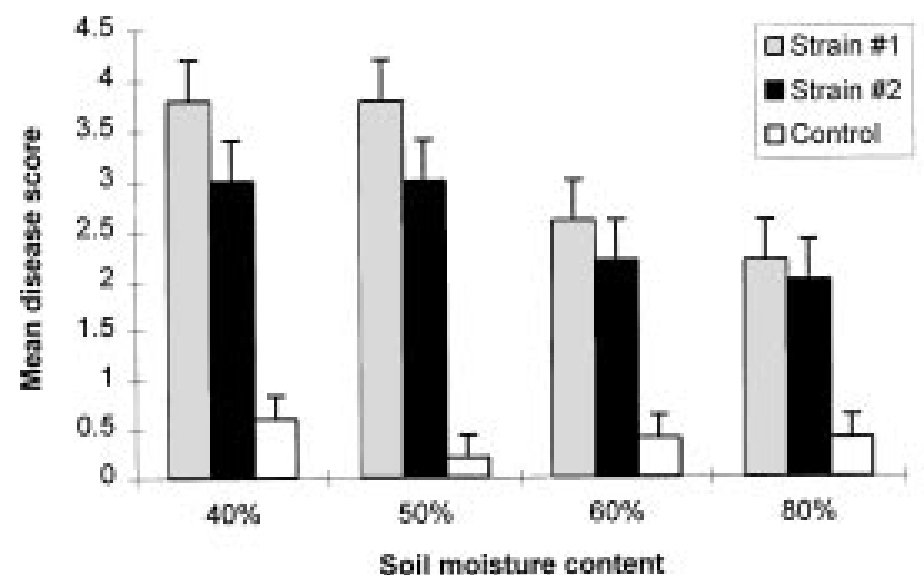

FIGURE 3: Mean root disease score of white clover plants inoculated with $C$. fertilis and maintained at different levels of soil moisture. Treatment error bars = pooled SEM, 0.41; Control error bars = pooled SEM, 0.23. 
Roots of inoculated plants had a high incidence of conspicuous disease symptoms such as discoloration, lesioning and root rot, symptoms of C. fertilis infection also found by Menzies (1973) and Campbell (1982). This is shown in Fig. 3 where inoculated plants had much higher disease scores than control plants. Roots were therefore more susceptible to damage and rot at low soil moisture contents. Clover plants growing in the field could be susceptible to the same damage that was demonstrated in this study, as low soil moisture contents (between 32-50\% WHC) have also been measured in Waikato pasture soils during summer (Waipara unpublished).

\section{CONCLUSION}

C. fertilis is a root-rot pathogen of white clover plants which can reduce root and shoot production of this economically important pasture forage legume. This fungus is potentially a contributing factor to poor persistence of clover in North Island pastures. Soil moisture is an important environmental factor which can influence the pathogenicity of the fungus. In dry soils where plants are already stressed, this pathogen could cause increased root damage leading to low pasture productivity and poor persistence.

\section{ACKNOWLEDGEMENT}

Dr Neil Cox assisted with statistical analysis.

\section{REFERENCES}

Campbell, L.C. 1980. Root rot of Ladino clover induced by Codinaea fertilis. Plant Dis. 64: 959-960.

Campbell, L.C. 1982. Cultural characteristics and host range of Codinaea fertilis. Phytopath. 72: 501-504.

Jenkinson, D.T. and Powlson, D. S. 1976a. Effects of biocidal treatments on metabolism in soil I. Fumigation with chloroform. Soil Biol. Biochem. 8: 167-177.

Jenkinson, D.T. and Powlson, D. S. 1976b. Effects of biocidal treatments on metabolism in soil V. A method for measuring soil biomass. Soil Biol. Biochem. 8: 209-213.

Leath, K. T., 1989. Diseases and forage stand persistence in the United States. Pp. 465478.In: Persistence of Forage Legumes. G.C. Marten, A.G. Matches, R.F. Barnes, R.W. Brougham, R.J. Clements and G.W. Sheath. (Eds). Madison, Wisconsin.

Menzies, S. A. 1973. Root rot of clover caused by Codinaea fertilis. N.Z. J. Agric. Res. 16: $239-245$.

Skipp, R.A. and Christensen, M.J., 1989. Fungi invading roots of perennial ryegrass (Lolium perenne L.) in pasture. N.Z. J. Agric. Res. 32: 423-431.

Skipp, R.A. and Christensen, M.J., 1983. Invasion of white clover roots by fungi and other soil microorganisms. IV. Survey of root-invading fungi and nematodes in some New Zealand pastures. N.Z. J. Agric. Res. 25: 97-101.

Skipp, R.A. and Christensen, M.J., 1982. Invasion of white clover roots by fungi and other soil microorganisms. III The capacity of fungi isolated from white clover roots to invade seedling root tissue. N.Z. J. Agric. Res. 25: 97-101.

Waipara, N. W., Di Menna, M. E., Cole, A. L. and Skipp, R. A. 1996. Potential pathogenicity of pasture plant root-colonising fungi to seedlings of legumes and grasses. Proc. 49th N.Z. Plant Prot. Conf. (this volume). 